\title{
Mulher para presidente do Brasil? Gênero e política na perspectiva do eleitor brasileiro
}

\begin{tabular}{c}
\hline \hline Simone R. Bohn \\
Department of Political Science \\
York University \\
\hline \hline
\end{tabular}

\begin{abstract}
Resumo: De acordo com alguns autores, o processo de modernização, além de provocar alterações sociais estruturais (como industrialização e urbanização e todos os seus efeitos correlatos), também concorre para a modificação do sistema de valores e atitudes tradicionais na direção da emergência de valores ditos modernos - ou seja, seculares e de auto-expressão. Dentre os últimos inclui-se a aceitação do princípio da igualdade de gênero. 0 objetivo deste artigo é verificar, mediante a análise do survey LAPOP.Brasil 2007, em que medida os cidadãos brasileiros - parte de uma sociedade moderna, porém de redemocratização recente - mostram-se favoráveis à participação eqüitativa da mulher na arena política formal. Os dados demonstram que, embora a maioria no Brasil seja, em tese, favorável, à participação eqüitativa da mulher na política, a rejeição do princípio da igualdade de gênero, quando ocorre, associa-se com valores e atitudes de conservadorismo moral e social e também de baixo apoio ao regime democrático, o que indica a permanência de bolsões de atitudes e valores tradicionais, conservadores e autoritários no interior da sociedade brasileira.
\end{abstract}

Palavras-chave: igualdade de gênero; modernização; valores; conservadorismo; autoritarismo.

\begin{abstract}
According to some authors, the modernization process, besides bringing about major changes in the social structure (such as industrialization, urbanization and all its related effects), also fosters changes in the system of traditional values and attitudes in the direction of emergence of the so-called modern values - secular and self-expression values. Among the latter, one would include the acceptance of the principle of gender equality. The goal of this article is to verify, through the analysis of the LAPOP. Brazil 2007 survey, the degree to which Brazilian citizens - part of a modern but recently democratized society - are favorable to the equitable participation of women in the formal political arena. The data show that, even though the majority in Brazil theoretically accepts the participation of women in politics, the rejection of the principle of gender equality, when occurs, is associated with social and moral conservative values and attitudes and with low support for democracy - which indicates that pockets of traditional, conservative and authoritarian values still predominates in the Brazilian society.
\end{abstract}

Keywords: gender equality; modernization; values; conservantism; authoritarianism. 
BOHN, S. R. Mulher para presidente do Brasil? Gênero e política...

\section{Introdução ${ }^{1}$}

Até que ponto os eleitores brasileiros estão dispostos a aceitar que uma mulher seja eleita e assuma o posto de Presidente da República do Brasil? Em que medida apóiam o princípio da igualdade de gênero na esfera política formal? 0 objetivo deste artigo é verificar se o sistema de valores, atitudes e comportamentos difundido entre os cidadãos brasileiros contém atitudes favoráveis à participação eqüitativa da mulher na política.

Por quê o tema da igualdade de gênero é socialmente relevante e importante como tópico de pesquisa acadêmica? Por pelo menos duas razões. Em primeiro lugar, iniqüidades de qualquer tipo - seja de gênero, racial, étnica, sexual etc. evidenciam a existência de estruturas de dominação que alteram significativamente um dos princípios fundamentais de sociedades democráticas, a igualdade de oportunidades entre os distintos grupos sociais (MARSHALL, 1950; TOCQUEVILLE, 1994). A permanência da desigualdade de gênero (ENLOE, 1989; FLAX, 1987; PETERSON e RUNYAN, 1999), em particular, aponta para a limitada democratização da sociedade, uma vez que indica que a democracia procedimental (SCHUMPETER, 1976) em vigor na arena política formal inexiste em outras esferas (BOBBIO, 1986), seja no ambiente doméstico, no mercado de trabalho ou no plano das relações sociais entre indivíduos. Quando isso ocorre, o mais democrata dos homens na res publica (ARISTÓTELES, 1998) mantém-se na condição de déspota privado (ARAÚJO e SCALON, 2006; BURNS, SCHLOZMAN e VERBA, 2001); desigualdades salariais entre homens e mulheres, no seu acesso às profissões modernas, no padrão de recrutamento e promoção perduram no mercado de trabalho (ENLOE, 2001; FRIEDAN, 1963; LOPES, 2006; MONROE, OZYURT, WRIGLEY e ALEXANDER, 2008); e valores sociais tradicionais obstaculizam a liberdade de ação da mulher (HTUN, 2003; JOHNSON, 2002; VARGAS, 2002; WAYLEN, 2003; WILLMOTT, 2002).

Em segundo lugar, há uma importante associação entre a aceitação da igualdade de gênero e a sedimentação de valores, atitudes e comportamentos favoráveis à democracia. Em diversas sociedades, a hostilidade em relação ao princípio da igualdade de gênero é acompanhada por valores, atitudes e comportamentos no plano social e/ou moral indicativos de intolerância em relação à diversidade social e de baixo apoio ao regime democrático no plano político. Em

\footnotetext{
1 Esse trabalho foi realizado com o apoio financeiro da International Development Research Centre (IDRC), Ottawa, Canadá. O LAPOP.Brasil 2007, survey no qual esse estudo se baseia, contou com o apoio financeiro do CNPq (Processo $n^{\circ}$ 477136/2006-0) e de generosas contribuições financeiras do Dr. Mitchell Seligson (Vanderbilt University, Diretor do LAPOP) e do Dr. David Samuels (University of Minnesota) - a quem agradeço imensamente. Agradeço também a Rachel Meneguello por seus comentários e sugestões feitos por ocasião do Seminário Internacional realizado na Universidade Federal de Goiás (Maio de 2008), onde os dados deste paper foram inicialmente apresentados.
} 
outras palavras, em algumas sociedades, há um contínuo entre valores tradicionais no que se refere aos papéis atribuídos aos gêneros, por um lado, e, por outro, atitudes indicativas de conservadorismo moral e social e de autoritarismo na esfera política.

O que deveríamos esperar em relação aos cidadãos brasileiros? De acordo com as várias vertentes da teoria da modernização, os diversos processos associados à passagem de comunidades agrárias para sociedades industriais (tais como a industrialização, a urbanização, a complexificação da estrutura ocupacional da sociedade, a elevação da qualidade do capital humano e a entrada massiva da mulher no mercado de trabalho) contribuem para a alteração do sistema de valores, para a disseminação de atitudes de tolerância, para a mudança da visão tradicional acerca dos papéis destinados a homens e mulheres e, em última instância, para a aceitação do princípio da igualdade de gênero (DEUTSCH, 1964; LERNER, 1958; LIPSET, 1959, 1960; ROSTOW, 1960). Como sociedade que passou por um rápido processo de modernização socioeconômica, esperamos, portanto, que, os eleitores brasileiros mostrem-se favoráveis não só à presença, como também à participação eqüitativa da mulher na arena política.

$\mathrm{Na}$ próxima seção, descrevemos o arcabouço explicativo da teoria da modernização, suas insuficiências e ganhos analíticos, na seção subseqüente, analisamos suas implicações para o caso brasileiro, testadas empiricamente. Através da análise dos dados do survey LAPOP-Brasil 2007, mostramos que um sistema de valores típicos de sociedades pré-modernas ainda encontra-se difuso entre uma minoria da sociedade brasileira, resultando não só na rejeição do princípio da igualdade de gênero no sistema político, mas também na permanência de atitudes intolerantes em relação à diversidade e de valores hostis à sedimentação da democracia no Brasil.

\section{Processo de modernização e seus efeitos no plano dos valores}

As primeiras teorizações a respeito do processo de modernização e suas implicações datam de pelo menos do final do século XVIII, tornaram-se populares no século seguinte e possuem uma clara inspiração darwiniana (BAKER, 1975). Em sua maioria, vêem a sociedade como um organismo e o "progresso social" como uma conseqüência inelutável de transformações econômicas que provocam a passagem de comunidades tradicionais para sociedades modernas (BOTTOMORE e NISBET, 1978).

Numa visão claramente organicista da sociedade, Durkheim (1997), por exemplo, considera que, tal como os seres vivos, as sociedades também possuem diversos estágios evolutivos, caracterizados sobretudo pela passagem de uma 
BOHN, S. R. Mulher para presidente do Brasil? Gênero e política...

divisão social do trabalho simples para uma cada vez mais complexa, típica de sociedades modernas, isto é, industrializadas. De acordo com ele, nem todas as conseqüências do processo de modernização são positivas, uma vez que este, ao erodir as antigas bases de coesão social, pode engendrar anomia social. Marx (1973) partilha dessa noção de evolução sociale e um exemplo disso é sua consideração de que as sociedades mais desenvolvidas (mais industrializadas) demonstram às menos desenvolvidas seu futuro próximo.

Já no século XX, Parsons, entre outros, retoma a idéia da existência de um progresso social, decorrente da passagem de agregações sociais mais simples para as mais complexas. De acordo com ele, existem dez "universais evolucionários", que nada mais são do que "um complexo de estruturas e processos associados" que "aumentam a capacidade adaptativa de longo prazo dos sistemas vivos" (PARSONS, 1999, p. 159). Além de uma economia monetizada de mercado e uma burocracia administrativa, o regime democrático figura como um dos "universais evolucionários", já que institucionaliza, segundo Parsons, os elementos necessários à perpetuação de sociedades complexas (tais como a racionalização e formalização de direitos, o desenvolvimento e proteção de um sistema de leis de escopo universalista e, sobretudo, a preservação dos direitos e liberdades necessários à manutenção de uma economia de mercado). Sob essa perspectiva, as sociedades do chamado "Globo Sul" (BELLO, 1994) não são consideradas como sendo totalmente modernas, uma vez que ainda não possuem todos os "universais evolucionários".

Muitas têm sido as críticas feitas aos fundamentos dessas visões sobre o processo de modernização. Diversos autores pontuam que eles se baseiam em uma perspectiva teleológica de desenvolvimento social - visível, por exemplo, em Brzezinski (1997), para quem as sociedades tradicionais aparecem constantemente em busca da reprodução dos processos experimentados por sociedades ditas modernas. Em segundo lugar, a passagem de comunidades tradicionais para sociedades modernas não se dá de forma unilinear, mas através de um processo multidimensional e sem um fim pré-determinado (GERMANI, 1981). Assim, agrupamentos sociais podem deteriorar-se ou não se modernizar completamente ou de maneira uniforme. Em terceiro lugar, essas visões do processo de modernização padecem de um excessivo economicismo, na medida em que postulam que a industrialização de setores econômicos necessariamente transforma uma sociedade tradicional em moderna (CARDOSO e FALETTO, 1979). Em quarto lugar, a própria dualidade entre tradicional e moderno é criticada (JOHNSTON, 1991), uma vez que não abre espaço para distinções e heterogeneidades subnacionais. Esses relatos do processo de modernização sofrem ainda de um a-historicismo excessivo, já que não são sensíveis às peculiaridades históricas de cada país e nem aos seus distintos pontos de partida. Ademais, a modernização aparece como sinônimo de 
"ocidentalização" (RANDALL e THEOBALD, 1985), o que faz com que esses relatos sejam taxados de etnocêntricos - especialmente em virtude de sua implícita anuência em relação às experiências colonialistas e neo-colonialistas (SAID, 1979).

No que diz respeito à questão de gênero especificamente, as teorias da modernização têm sido criticadas sob vários ângulos. Em primeiro lugar, a maioria delas - embora não todas - mantém a separação estrita, comum ao pensamento ocidental, entre o domínio público e a esfera privada, de modo que são poucas as elaborações a respeito do impacto do processo de modernização sobre a estrutura familiar e sobre o papel da mulher nesta última (SCOTT, 1995). Em segundo, avanços tecnológicos nem sempre concorrem para a melhora da condição feminina, algo implícito nas teorias da modernização. Boserup (1974, apud JAQUETTE, 1982), por exemplo, argumenta que as mudanças tecnológicas que propiciaram a passagem de uma agricultura de subsistência para um empreendimento comercial monetarizado foram predominantemente negativas para as mulheres, na medida em que elas perderam sua condição de comerciante e sua mobilidade espacial e foram confinadas ao ambiente doméstico. Além disso, a entrada da mulher no mercado de trabalho industrial se deu sob condições de extrema exploração (MARSHALL, 1950) - algo com ramificações contemporâneas, dada a massiva presença do contigente feminino no mercado de trabalho informal (CARREIRA, 2004; ENLOE, 1992, 2000). Finalmente, muitas vertentes da teoria da modernização são problemáticas porque se calam a respeito da questão da mulher e do seu papel no processo de desenvolvimento socioeconômico e cultural, uma vez que vêem as mulheres "como reprodutoras e não produtoras; como casos de assistência social e não como trabalhadoras" (JAQUETTE, 1982, p.271).

No entanto, a despeito dessas críticas, ao longo dos anos tem se acumulado evidência empírica robusta (INGLEHART, 1977, 1990, 1997; INGLEHART e BAKER, 2000; INGLEHART e NORRIS, 2003, 2005; INGLEHART e WETZEL, 2005) de que, apesar de sua não-linearidade e intrínseca heterogeneidade, o processo de modernização, entendido como a passagem de sociedades predominantemente agrárias para sociedades industriais (e, mais tarde, pós-industriais), de fato, produz alterações significativas no sistema de valores difuso entre os membros dos diversos agrupamentos sociais. Há nítidas diferenças em termos de valores entre sociedades mais e menos desenvolvidas economicamente. Inglehart e Baker (2000) e Inglehart e Norris (2003, 2005) revelam que em "sociedades pós-industriais" (BELL, 1973), por exemplo, valores seculares, racionais e de "auto-expressão" tendem a predominar, ao passo que em sociedades agrárias, valores tradicionais e "de sobrevivência" são prevalentes. De acordo com Inglehart (1990, 1997), valores tradicionais balizam-se na necessidade de se garantir a sobrevivência material e na centralidade da religião como código de normas regulador das relações sociais, enfatizam o respeito à autoridade e o papel central do homem nas mais diversas 
BOHN, S. R. Mulher para presidente do Brasil? Gênero e política...

esferas de interação social e tendem a resultar em atitudes autoritárias no plano político. Valores pós-materialistas, típicos de sociedades pós-industriais, por sua vez, centram-se não em temas relacionados à sobrevivência material, mas em temas relativos à qualidade de vida, tais como a preocupação com o meio ambiente e a defesa e o respeito à diversidade social (seja religiosa, étnica, racial, de gênero, de sexualidade etc.). Nas chamadas "sociedades do conhecimento" (as sociedades pós-industriais), em contraste com sociedades industriais também há amplo espaço para a auto-expressão do indivíduo, uma vez que, em economias de serviço ou baseadas no conhecimento, "a inovação e a liberdade para exercitar julgamento individual são essenciais" (INGLEHART e BAKER, 2000, p.22).

Apesar da associação significativa entre transformações socioeconômicas e modificações no sistema de valores sociais visível nesses estudos, a maioria deles, por outro lado, enfatiza que: 1) a alteração do sistema de valores é path dependent, isto é, o contexto (cultural, histórico, econômico, social, político) prévio influencia a natureza e a velocidade da transformação ocorrida (INGLEHART e NORRIS, 2005; STEEL e KABASHIMA, 2008); 2) pode haver diferenças consideráveis no plano subnacional em qualquer uma das sociedades em mutação (ADAMS e ORLOFF, 2005); e 3) a mudança no sistema valorativo de uma sociedade ocorre de maneira gradual e, de forma alguma, envolve a rápida substituição de um conjunto de valores por outro (INGLEHART e WETZEL, 2005).

A despeito desses atenuantes, que parcialmente respondem às críticas tradicionalmente feitas aos partidários das teorias da modernização, o importante a mencionar, sob a ótica deste artigo, é que esses estudos apontam para uma clara modificação a respeito dos papéis usualmente atribuídos aos gêneros. Eles afirmam que, inequivocamente, a aceitação da igualdade de gênero predomina em sociedades economicamente mais desenvolvidas. Como afirmam Inglehart e Norris, nesses países: "[a] ênfase na igualdade de gênero é parte de uma síndrome mais ampla de tolerância em relação a minorias, incluindo estrangeiros, gays e lésbicas" (INGLEHART e NORRIS, 2005, p.484). Em outras palavras, a aceitação da participação eqüitativa da mulher nos mais diferentes âmbitos sociais caminha lado a lado com o aumento do respeito e da anuência a quaisquer tipos de diversidade social.

Quais são as implicações desses estudos para o caso brasileiro? As décadas de 1940 a 1970 foram um período de rápida modernização econômica e transformação social no país (ALMEIDA, 1998; JAGUARIBE, 1985; SANTOS, 1986). O Brasil passou de um país no qual a maior parte dos cidadãos vivia na zona rural para uma sociedade em que $81 \%$ dos seus habitantes vivem em áreas urbanas (IBGE, 2000). Em 1940, 66\% da população economicamente ativa (PEA) trabalhava no setor agrícola (ALMEIDA, 1998). Desde 1980, no entanto, o setor de serviços emprega a maior porcentagem da PEA. Os indicadores sociais também 
apresentaram melhora significativa. A taxa de analfabetismo, por exemplo, declinou de 61\% na década de 1940 para 13,6\% em 2000; o nível de mortalidade infantil passou de 162 por mil em 1940 (IBGE, 1999) para 36 por mil em 2000 (IBGE, 2003) e a expectativa de vida do brasileiro ao nascer passou de 42 anos (1940) para 71,3 em 2003 (ALMEIDA, 1998; IBGE, 2003).

Desse modo, deveríamos esperar, portanto, que os cidadãos brasileiros exibissem valores típicos de sociedades não-tradicionais e tendessem, em sua maior parte, a aceitar a igualdade de gênero. Inglehart e Norris (2003, p.34), por exemplo, consideram o Brasil como uma das "muitas nações industrializadas de renda média" que figuram no meio da escala entre os países que mais e os que menos aceitam o princípio da igualdade de gênero. No entanto, os mesmos autores, na trilha de Sen (1999a) e de muitos outros, advertem para o fato de que nem sempre crescimento econômico e aumento da renda per capita média se traduzem em melhoras na qualidade de vida. Sob essas circunstâncias, nem todos os benefícios associados ao processo de modernização socioeconômica - como o aumento dos níveis de escolaridade e a melhora dos indicadores sociais (índice de desnutrição, de mortalidade infantil etc.) - estão presentes ou não se difundem para a maior parte da população:

\footnotetext{
"Amartya Sen estabeleceu uma importante e influente distinção entre a aquisição de renda e riqueza e a noção mais ampla de desenvolvimento humano, sendo que a última contém importantes indicadores de bem-estar social (...). O crescimento econômico pode influenciar estas condições, mas, mesmo em nações afluentes, pode haver bolsões de desigualdade social e redes de proteção social inadequadas. Há contrastes claros entre economias de elevado crescimento, como a Coréia do Sul, que tem tido considerável sucesso em aumentar a qualidade de vida, e outras, como o Brasil, que têm uma história de desigualdade social severa, desemprego e negligenciamento da saúde pública" (INGLEHART e NORRIS, 2003, p.35).
}

Em outras palavras, apesar de não haver dúvidas em relação à efetiva modernização da economia brasileira, sabe-se que as conseqüências sociais desta não atingiram todos os setores socioeconômicos de forma similar. O que não se sabe claramente é o impacto dessa heterogeneidade no plano dos valores. Ou seja, precisamos aferir até que ponto essas desigualdades obstaculizaram a difusão, entre a população brasileira, de valores "modernos", ou mesmo pós-materialistas (isto é, típicos de sociedades pós-industriais). Nesse sentido, a nossa expectativa é que, como sociedade modernizada, a maior parte da população esboce valores modernos como a igualdade de gênero, mas que também haja uma minoria resistente a esses princípios. Se essa expectativa estiver correta, precisaremos 
BOHN, S. R. Mulher para presidente do Brasil? Gênero e política...

saber qual é o tamanho dessa minoria, seu perfil e também se a não-aceitação da igualdade de gênero é acompanhada por outras atitudes e valores tradicionais e autoritários, tais como a intolerância em relação à diversidade social e o fraco apoio ao regime democrático.

\section{Desenho de pesquisa: hipótese e variáveis}

O objetivo fundamental deste artigo é entender se a população brasileira é ou não favorável ao princípio da igualdade de gênero. Apoiando-nos nos fragmentos da teoria da modernização aqui apresentados, esperamos, conforme mencionado anteriormente, que a maioria da população aceite a participação eqüitativa da mulher no universo político formal. Para responder a esta questão, baseamo-nos nos dados do survey do LAPOP-Brasil, 2007.

Como indicador da aceitação da igualdade de gênero na arena política, utilizamos uma pergunta do questionário LAPOP.Brasil 2007 que indaga se o entrevistado votaria ou não em uma mulher para presidente do Brasil. Acreditamos que a importância dessa questão é irrefutável, dada a centralidade do cargo de Presidente da República no contexto histórico, político e cultural brasileiro.

Além de analisarmos as razões pelas quais os brasileiros votariam ou não em uma mulher, procuramos mapear o perfil dos respondentes em termos de gênero, idade, renda, grau de escolaridade, nível de confiança interpessoal, estoque de capital social, opinião e atitude a respeito da homossexualidade e apoio ao regime democrático.

Em relação à idade, a nossa expectativa é que exista um corte geracional significativo. Ou seja, esperamos que quanto mais avançada a idade dos entrevistados, menor será seu apoio ao princípio da igualdade de gênero - sempre medida pela questão a respeito do voto em uma mulher para presidente do Brasil. Cidadãos mais idosos, em sua maioria, foram socializados em contextos sociais pré-modernos e, portanto, tendem a reter atitudes, valores e comportamentos típicos dessas circunstâncias sociais. Os mais jovens, por outro lado, não só não vivenciaram o mesmo processo de socialização - tendem a ter crescido em áreas urbanas e a ter alcançado maior nível educacional -, como também fazem parte de um país mais afluente e de uma economia em que o setor de serviços cresce a cada dia e em que as características de uma "sociedade do conhecimento" tornam-se cada vez mais visíveis. Na linguagem de Inglehart (1990 e 1997), valores secularesracionais e de auto-expressão tendem a predominar entre o último segmento social. Diversos estudos demonstram esse ponto. De acordo com Inglehart e Norris (2003), os cidadãos mais idosos, de maneira significativa estatisticamente, aceitam em 
menor grau a idéia da igualdade de gênero. E isso é válido tanto para sociedades predominantemente agrárias quanto para industriais e pós-industriais.

Por razões óbvias, em relação à variável gênero, esperamos que as mulheres aceitem em maior grau o princípio da igualdade de gênero do que os homens. Afinal, essa desigualdade afeta o segmento feminino negativamente. No que se refere à renda e educação, nossa expectativa é que a participação eqüitativa da mulher seja esposada mais entusiasticamente por cidadãos mais afluentes e com maior nível de escolaridade. Na maioria dos países - embora não necessariamente em sociedades com elevado grau de injustiça social - essas duas variáveis estão correlacionadas. Além disso, como indicam Davis e Robinson (1991), maior grau de escolarização revela maior conhecimento da desigualdade de gênero, nos âmbitos educacional e social, mas sobretudo no mercado de trabalho, e gera maior propensão a que homens e mulheres mostrem-se favoráveis à participação eqüitativa da mulher em todas as esferas.

Esperamos também que indivíduos com maior nível de confiança interpessoal e com maior estoque de "capital social" (BOURDIEU, 1986; COLEMAN, 1988 e 1994; PUTNAM, 1993, 1995, 1996 e 2000) sejam mais receptivos ao princípio da igualdade de gênero. Isso porque a participação em associações cívicas a dimensão mais estrutural da noção de capital social (PALDAM, 2000), além de promover habilidades e aptidões essenciais à criação de laços e redes entre os indivíduos da sociedade civil, aumenta o grau de confiança interpessoal e também contribui para a disseminação de valores e atitudes de tolerância e respeito em relação à diversidade - inclusive de gênero -, que são essenciais ao funcionamento do regime democrático (PUTNAM, 1993)2 ${ }^{2}$ O nível de confiança interpessoal - a dimensão cognitiva de capital social (BARBER, 1983; FUKUYAMA, 1997) -, entretanto, pode ser mais do que uma variável interveniente. Inglehart e Baker (2000), por exemplo, afirmam que sociedades nas quais o grau de confiança interpessoal é baixo são também nações em que o grau de apoio à igualdade de gênero é pequeno.

Como também testamos a sub-hipótese de que indivíduos hostis ao princípio da participação eqüitativa da mulher no universo político formal possuem valores tradicionais nos planos social e político (INGLEHART e NORRIS, 2003), nossa expectativa é que essas pessoas tenham opiniões e atitudes hostis à homossexualidade apóiem em menor grau o regime democrático.

O quê revelam os dados?

\footnotetext{
2 É importante mencionar que diversos trabalhos mostram que a noção de capital social não é neutra do ponto de vista de gênero. Ou seja, há diferenças significativas no nível e no tipo de associativismo cívico entre mulheres e homens (GIDENGIL e O'NEILL, 2006; LOWNDES, 2000; MOLYNEUX, 2002).
} 
BOHN, S. R. Mulher para presidente do Brasil? Gênero e política...

\section{Análise dos dados}

Quando perguntados sobre se considerariam votar em uma mulher para presidente do Brasil, $88 \%$ dos entrevistados responderam positivamente. Ou seja, apenas uma pequena minoria de um pouco mais de um décimo da amostra revelase hostil ao princípio da participação igualitária da mulher na política.

Contrariamente à nossa expectativa, no entanto, não existem diferenças estatisticamente significantes entre homens e mulheres a respeito dessa questão. Cerca de $88,7 \%$ do eleitorado feminino votaria em uma mulher para presidente. Entre os homens, a porcentagem é de $87,0 \%$. Como essa diferença de um pouco menos de $2 \%$ não é significativa do ponto de vista estatístico, não podemos afirmar que a variável gênero sozinha tenha poder preditivo a respeito da opinião de um indivíduo sobre a igualdade de gênero. A intersecção entre gênero e raça - apesar de aparentemente indicar que mulheres brancas são o grupo que apóia a igualdade de gênero em maior grau - também não produz resultados que obtêm significância estatística (Tabela 1$)^{3}$.

O mesmo se aplica à intersecção entre gênero, raça e classe social (Tabela 2). A última é aferida pela renda mensal individual. Nenhum dos resultados é estatisticamente significante - os que mais se aproximam de um grau de significância são os dados para mulheres brancas de classe média e homens brancos de classe alta. Diante disso, não temos como saber se, por exemplo, o apoio à participação eqüitativa da mulher entre as mulheres negras de classe baixa é realmente maior do que o de outros grupos pertencentes à mesma classe social. Ou se, entre os indivíduos de classe média, mulheres brancas são as pessoas que portam valores de gênero igualitários em maior grau. Ou ainda, se mulheres brancas das classes superiores são as menos igualitárias na comparação com os seus pares. Diante disso, retomamos essas intersecções na análise multivariada à frente.

\footnotetext{
${ }^{3}$ Muitos trabalhos advocam a importância do uso da interseccionalidade na análise de questões que envolvam uma perspectiva de gênero. Por exemplo: Brewer (1999); Crenshaw (1991 e 1993), Collins (1990 e 1998); Ferber (1998) e Weldon (2008).
} 
Tabela 1 - Gênero, raça ${ }^{1}$ e porcentagem dos que votariam em uma mulher para presidente

\begin{tabular}{|l|c|c|c|}
\hline Grupo Social & \% & Pearson chi2 (1) & Pr \\
\hline Negros & 84,8 & 2.4003 & 0.121 \\
\hline Brancos & 89,8 & 1.9872 & 0.159 \\
\hline Mulheres negras & 87,5 & 0.3290 & 0.566 \\
\hline Mulheres brancas & 91,9 & 3.1524 & 0.076 \\
\hline Homens negros & 82,4 & 2.3003 & 0.796 \\
\hline Homens Brancos & 87,7 & 0.0667 & 0.129 \\
\hline
\end{tabular}

${ }^{1}$ Pergunta: "O IBGE - instituto que faz os censos no Brasil - usa os termos negro, pardo, branco, amarelo e índio para classificar a cor ou raça das pessoas. Qual desses termos descreve melhor a sua cor ou raça: 1 Negro; 2 Pardo; 3 Branco; 4 Amarelo; 5 Índio; 88 NS; 99 NR?".

Fonte: LAPOP-Brasil, 2007.

\section{Tabela 2 - Gênero, raça ${ }^{1}$, classe ${ }^{2}$ e porcentagem dos que votariam em uma mulher para presidente}

\begin{tabular}{|c|c|c|c|c|}
\hline Gênero e Raça & Classe baixa & $\begin{array}{c}\text { Classe média } \\
\text { baixa }\end{array}$ & Classe média & Classe Alta \\
\hline Mulheres Negras & 91,1 & 81,5 & 87,5 & 100,0 \\
\hline Mulheres Brancas & 90,2 & 87,3 & $98,2^{*}$ & 91,3 \\
\hline Homens Negros & 82,3 & 92,3 & 81,2 & 100,0 \\
\hline Homens Brancos & 89,2 & 86,4 & 90,0 & $100,0^{* *}$ \\
\hline
\end{tabular}

* Pearson chi2 $(1)=4.2706 \mathrm{Pr}=0.039$; * Pearson chi2(1) $=2.8698 \mathrm{Pr}=0.090$.

${ }^{1}$ Vide Tabela 1.

2 Pergunta: "Qual é a sua renda mensal pessoal?" As respostas foram codificadas da seguinte forma: a) até 1 salário mínimo como "classe baixa" (=1) [37,9\% da amostra]; b) entre 1 e 2 salários mínimos como "classe média baixa" (=2) [31,5\%]; c) entre 2 e 5 salários mínimos como "classe média" $(=3)[23,1 \%]$ e d) acima de 5 sálarios mínimos como "classe alta2" $(=4)[7,6 \%]$. Por questões de densidade estatística, especificamente para esta tabela, agregamos no último grupo duas categorias: i.) "classe média alta", que corresponde a 5,8\% da amostra e inclui indivíduos cujo ganho mensal é entre 5 e 10 salários mínimos; e ii.) "classe alta", que equivale a 1,8\% da amostra e envolve pessoas com renda mensal acima de 10 salários mínimos. Na Tabela 3, essas duas últimas categorias são usadas no lugar da categoria "d" ou "classe alta2", que representa a agregação das mesmas.

Fonte: LAPOP-Brasil, 2007. 
BOHN, S. R. Mulher para presidente do Brasil? Gênero e política...

Da mesma forma, em uma análise bivariada, a variável renda, tal como gênero, sozinha, não é estatisticamente significante. Quais são os grupos a respeito dos quais podemos tecer considerações mais robustas?

Os subgrupos sociais que menos tendem a aceitar a participação eqüitativa da mulher no universo político formal são pessoas idosas e indivíduos com baixo nível educacional. Consonante ás teorias sobre os efeitos geracionais do processo de modernização - que afirmam que o processo de socialização em sociedades tradicionais torna as pessoas da terceira idade menos receptivas ao princípio da igualdade de gênero -, constatamos que quanto mais jovens os indivíduos, mais tendem a esposar visões igualitárias sobre a questão da participação da mulher na política. Desse modo, ao passo que 94,2\% das pessoas entre 18 e 30 anos mostram-se dispostas a votar em uma mulher para presidente do Brasil, entre os indivíduos acima de 60 anos, esse número cai para 70,5\% (Gráfico 1). Esta diferença de mais de $23 \%$ é significativa do ponto de vista estatístico, o que indica que os dados sobre o Brasil corroboram a perspectiva de que há um claro corte geracional no que se refere à manifestação de valores igualitários em relação ao gênero.

O nível educacional também possui, quando tomado isoladamente (isto é, em uma análise bivariada), um impacto significativo no sistema valorativo dos indivíduos - tal como apontam Araújo e Scalon (2006). Entre os analfabetos e indivíduos que completaram até a antiga quarta série do agora ensino fundamental, o apoio à participação igualitária da mulher no universo político formal alcança os níveis de $66,1 \%$ e $77,3 \%$, respectivamente (Gráfico 2). Entre os que completaram o ensino superior, o grau de apoio é quase um terço maior, é de 100,0\%. Esta diferença demonstra que os ganhos em termos de desenvolvimento de capital humano associados ao processo de modernização traduzem-se, de fato, no plano de valores, atitudes e comportamentos, na adoção de posturas mais igualitárias. 
Gráfico 1 - Idade e porcentagem dos que votariam em uma mulher para Presidente do Brasil

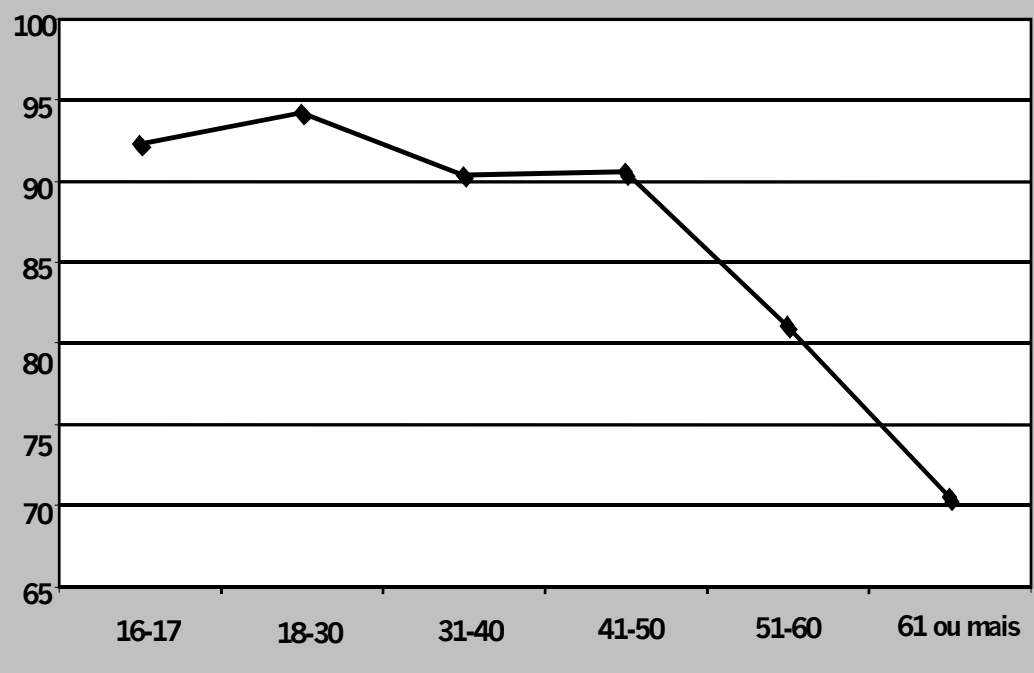

Fonte: LAPOP-Brasil, 2007.

Gráfico 2 - Educação e porcentagem dos que votariam em uma mulher para Presidente do Brasil

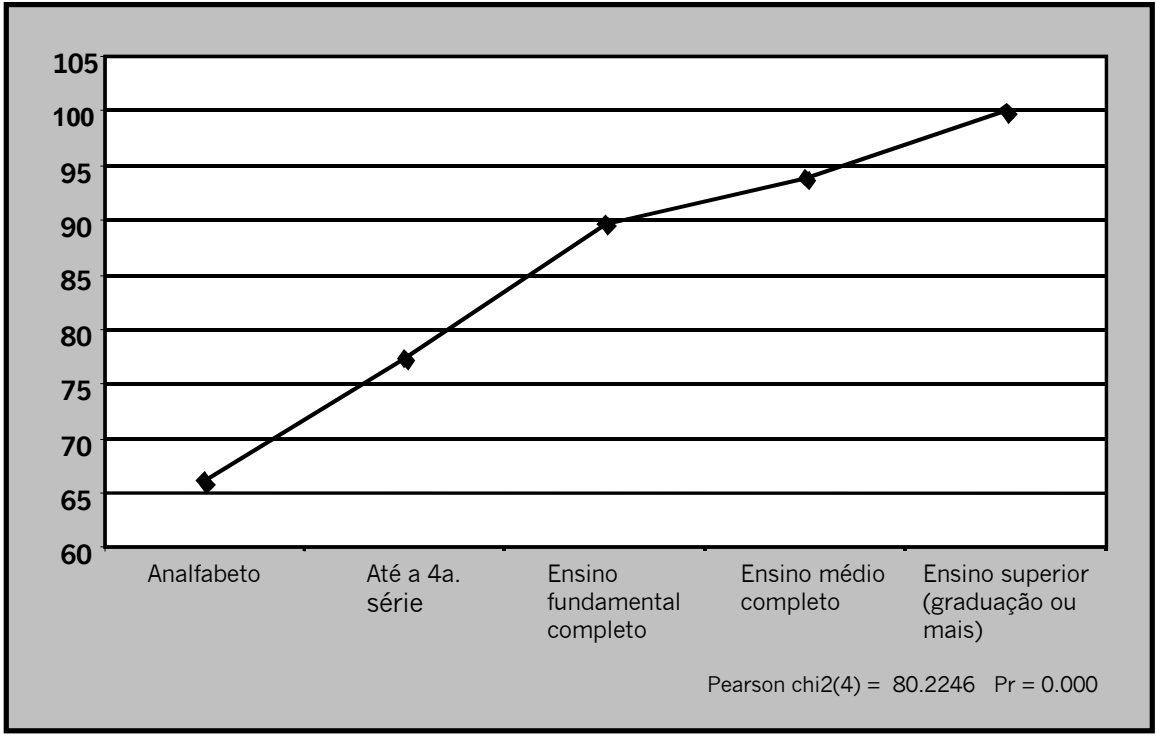

Fonte: LAPOP-Brasil, 2007. 
BOHN, S. R. Mulher para presidente do Brasil? Gênero e política...

Por que os indivíduos votariam ou não em uma mulher para presidente do Brasil? Há contrastes visíveis (todos estatisticamente significantes) entre esses dois grupos (Gráfico 3). Entre os cidadãos brasileiros dispostos a alçar uma mulher ao cargo público executivo máximo do país, as principais razões listadas para justificar sua escolha são a de que o gênero do candidato é irrelevante no processo de decisão eleitoral $(97,6 \%)$ e a de que a competência $(96,5 \%)$, o caráter $(91,5 \%)$ e o programa do candidato $(87,3 \%)$ são os atributos ou elementos importantes. Além disso, entre os que votariam em uma mulher na disputa presidencial, 89,4\% consideram que "todos os políticos são iguais". Este último número é impressionante, uma vez que, em outros sistemas políticos, uma das principais fontes de apelo de mulheres candidatas é seu diferencial em relação aos homens candidatos - seja no que se refere à percepção de que são ou serão menos corruptas no exercício do mandato ou à de que elas possuem melhores propostas de políticas públicas, sobretudo na área social (GULATI, 2004; GROSSI e MIGUEL, 2001; ONDERCIN e WELCH, 2005).

\section{Gráfico 3 - Por que votaria ou não em uma mulher?}

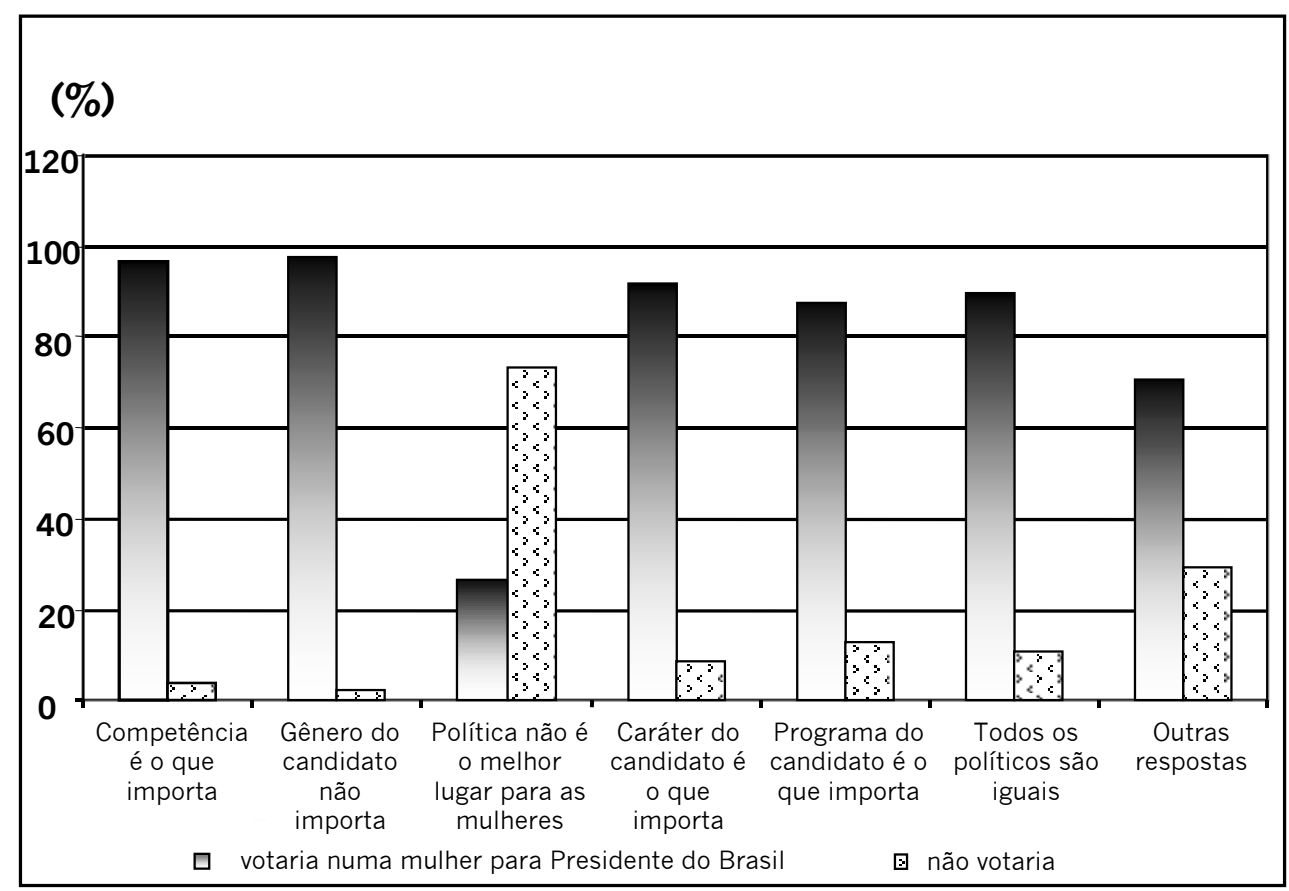

Fonte: LAPOP-Brasil, 2007. 
Já entre os eleitores que rejeitam, ou aceitam em menor grau, o princípio da igualdade de gênero na arena política, $73,2 \%$ deles afirmam explicitamente que "a política não é o melhor lugar para mulheres". Este dado indica claramente que esses indivíduos partilham de valores tradicionais, que automaticamente subscrevem a cada um dos gêneros arenas específicas de interação social. Sob essa perspectiva, portanto, a mulher é inadequada à política como profissão, uma vez que esta última é um domínio essencialmente masculino. Em outras palavras, este dado revela a permanência de uma visão extremamente patriarcal do universo político (BENNETT e BENNETT, 1999; BURRELL, 1994; FINAMORE e CARVALHO, 2006; SANBONMATSU, 2002) entre segmentos do eleitorado brasileiro.

Até o momento, vimos que nossa hipótese principal se confirma. Ou seja, como membros de uma sociedade moderna, a maioria dos brasileiros é favorável à participação eqüitativa da mulher no sistema político formal. Observamos também que uma minoria - que, conforme mencionado, corresponde a aproximadamente $12 \%$ do total - não partilha dessa perspectiva. Resta-nos agora verificar se essa minoria, além de hostil à idéia da igualdade de gênero, partilha de valores tradicionais em outras esferas: no plano social e no que se refere ao regime político.

Com esse objetivo, realizamos uma análise probit com os determinantes de valores igualitários em relação ao gênero. Nessa análise, codificamos a rejeição do princípio da igualdade de gênero como "um" e a aceitação como "zero". Na mesma linha do que fizemos anteriormente, assumimos que todos os eleitores que não votariam em uma mulher para presidente do Brasil rejeitam o valor da igualdade entre os sexos na esfera política.

Além das variáveis mencionadas incluímos sete outras. Cinco delas são opiniões a respeito da igualdade de gênero em diferentes esferas - política, educacional e no mercado de trabalho -, aferidas pelo grau de concordância ou discordância em relação às seguintes frases: "os homens são mais adequados para a carreira política", "os homens governam melhor dos que as mulheres", "as mulheres ainda não têm experiência suficiente para governar", "quando o desemprego é elevado, os homens têm mais direito ao trabalho do que as mulheres" e "um diploma universitário é mais essencial aos homens do que às mulheres". As outras duas questões buscam mensurar o grau de tolerância em relação a outras minorias - como os homossexuais - e o nível de apoio ao regime democrático no Brasil. O objetivo é utilizar essas últimas duas variáveis como possíveis indicações de conservadorismo no plano social e autoritarismo no plano político. 
A Tabela 3 contém os resultados da análise. Como vemos, ceteris paribus, idade e educação continuam sendo importantes preditores sócio-demográficos do fenômeno em tela. Ganhos na escala de educação aumentam significativamente a probalidade de aceitação do princípio da igualdade de gênero. De fato, a passagem de um nível educacional para o imediatamente superior diminui em cerca de 2,1\% a chance de um indivíduo rejeitar a idéia de uma participação igualitária da mulher no universo político ${ }^{4}$.

Tabela 3 - Análise de probit sobre a rejeição do princípio da igualdade de gênero

\begin{tabular}{|c|c|c|c|}
\hline Variáveis & Modelo 1 & Modelo 2 & Modelo 3 \\
\hline $\begin{array}{l}\text { Idade } \\
(16-17 \text { anos }=1 ; 61 \text { anos ou mais }=6)\end{array}$ & $\begin{array}{l}.1213^{* *} \\
(.0553)\end{array}$ & $\begin{array}{l}.1621^{* *} \\
(.0561)\end{array}$ & $\begin{array}{l}.1466^{* *} \\
(.0453)\end{array}$ \\
\hline $\begin{array}{l}\text { Educação } \\
(\text { analfabeto }=1 ; \text { superior ou mais }=5)\end{array}$ & $\begin{array}{l}-.1624^{*} \\
(.0810)\end{array}$ & $\begin{array}{l}-.1589 \\
(.0813)\end{array}$ & $\begin{array}{l}-.1630 * \\
(.0676)\end{array}$ \\
\hline $\begin{array}{l}\text { Renda } \\
\text { (até } 1 \text { salário mínimo [s.m.] = 1; dez ou mais s.m. = 5) }\end{array}$ & $\begin{array}{l}.0562 \\
(.0782)\end{array}$ & $\begin{array}{l}.0414 \\
(.0805)\end{array}$ & \\
\hline $\begin{array}{l}\text { Homens são mais adequados para a carreira política } \\
\text { (concorda muito }=1 \text {; discorda muito }=5 \text { ) }\end{array}$ & $\begin{array}{l}-.0145 \\
(.0765)\end{array}$ & $\begin{array}{l}.0178 \\
(.0773)\end{array}$ & \\
\hline $\begin{array}{l}\text { Homens governam melhor do que mulheres } \\
\text { (concorda muito }=1 ; \text { discorda muito }=5 \text { ) }\end{array}$ & $\begin{array}{l}.0550 \\
(.0792)\end{array}$ & $\begin{array}{l}.0558 \\
(.0790)\end{array}$ & \\
\hline $\begin{array}{l}\text { As mulheres ainda não têm experiência suficiente para governar } \\
\text { (concorda muito }=1 \text {; discorda muito }=5 \text { ) }\end{array}$ & $\begin{array}{l}-.1927^{* *} \\
(.0739)\end{array}$ & $\begin{array}{l}-.1858^{*} \\
(.0735)\end{array}$ & $\begin{array}{l}-2.596 * * * \\
(.0532)\end{array}$ \\
\hline $\begin{array}{l}\text { Quando o desemprego é elevado, homens têm mais direito ao } \\
\text { trabalho (concorda muito }=1 \text {; discorda muito }=5 \text { ) }\end{array}$ & $\begin{array}{l}-.2111^{* *} \\
(.0727)\end{array}$ & $\begin{array}{l}-.2110^{* *} \\
(.0730)\end{array}$ & $\begin{array}{l}-.2054^{* * * *} \\
(.0524)\end{array}$ \\
\hline $\begin{array}{l}\text { Um diploma universitário é mais essencial aos homens do que } \\
\text { às mulheres (concorda muito }=1 \text {; discorda muito }=5 \text { ) }\end{array}$ & $\begin{array}{l}.0031 \\
(.0762)\end{array}$ & $\begin{array}{l}.0090 \\
(.0756)\end{array}$ & \\
\hline $\begin{array}{l}\text { Confiança interpessoal (confia muito nos outros = } 1 \text {; os outros } \\
\text { não são confiáveis }=4 \text { ) }\end{array}$ & $\begin{array}{l}.0825 \\
(.0779)\end{array}$ & $\begin{array}{l}.0778 \\
(.0782)\end{array}$ & \\
\hline $\begin{array}{l}\text { Estoque de capital social } \\
(\text { baixo }=1 ; \text { elevado }=0)\end{array}$ & $\begin{array}{l}.3051^{*} \\
(.1528)\end{array}$ & $\begin{array}{l}.3259 * \\
(.1525)\end{array}$ & $\begin{array}{l}.3484^{* *} \\
(.1340)\end{array}$ \\
\hline $\begin{array}{l}\text { Atitude em relação à homossexualidade }{ }^{1} \\
\text { (intolerância }=1 ; \text { tolerância }=0 \text { ) }\end{array}$ & $\begin{array}{l}.1529 \\
(.1439)\end{array}$ & $\begin{array}{l}.1481 \\
(.1448)\end{array}$ & $\begin{array}{l}.2778^{*} \\
(.1257)\end{array}$ \\
\hline $\begin{array}{l}\text { Apoio à democracia } 2 \\
(\text { baixo }=1 ; \text { elevado }=0)\end{array}$ & $\begin{array}{l}.2784 \\
(.1447)\end{array}$ & $\begin{array}{l}.2896^{*} \\
(.1460)\end{array}$ & $\begin{array}{l}.3420 * * \\
(.1259)\end{array}$ \\
\hline
\end{tabular}

\footnotetext{
${ }^{4}$ Renda e educação não geraram o problema de multicolinearidade nos modelos 1 e 2.
} 
Tabela 3 - Análise de probit sobre a rejeição do princípio da igualdade de gênero

\begin{tabular}{|c|c|c|c|}
\hline Variáveis & Modelo 1 & Modelo 2 & Modelo 3 \\
\hline $\begin{array}{l}\text { Homem Branco } \\
(=1 ; \text { outros }=0)\end{array}$ & $\begin{array}{l}.1483 \\
(.1982)\end{array}$ & & \\
\hline $\begin{array}{l}\text { Homem Negro } \\
(=1 ; \text { outros }=0)\end{array}$ & $\begin{array}{l}.1373 \\
(.2825)\end{array}$ & & \\
\hline $\begin{array}{l}\text { Mulher Branca } \\
(=1 ; \text { outros }=0)\end{array}$ & $\begin{array}{l}.0220 \\
(.1768)\end{array}$ & & \\
\hline $\begin{array}{l}\text { Mulher Negra } \\
(=1 ; \text { outros }=0)\end{array}$ & $\begin{array}{l}.3542 \\
(.2589)\end{array}$ & & \\
\hline $\begin{array}{l}\text { Branco } \\
(=1 ; \text { outros }=0)\end{array}$ & & $\begin{array}{l}. .2112 \\
(.1488)\end{array}$ & $\begin{array}{c}-2.4462^{*} \\
(.1204)\end{array}$ \\
\hline $\begin{array}{l}\text { Negro } \\
(=1 ; \text { outros }=0)\end{array}$ & & $\begin{array}{l}.1355 \\
(.1836)\end{array}$ & \\
\hline Constante & $\begin{array}{l}.1358 \\
(.5220)\end{array}$ & $\begin{array}{l}.1702 \\
(.5307)\end{array}$ & $\begin{array}{l}.1762 \\
(.4130)\end{array}$ \\
\hline $\begin{array}{l}\text { N } \\
\text { Prob > chi2 } \\
\text { Pseudo R2 }\end{array}$ & $\begin{array}{l}886 \\
0.000 \\
.1985\end{array}$ & $\begin{array}{l}886 \\
0.000 \\
.2012\end{array}$ & $\begin{array}{l}1096 \\
0.000 \\
.2227\end{array}$ \\
\hline
\end{tabular}

${ }^{*} \mathrm{p}<.05,{ }^{* *} \mathrm{p}<.01, \mathrm{e}^{* * *} \mathrm{p}<.001$.

- Pergunta: "No último ano o sr./sra. contribuiu para a solução de algum problema de sua comunidade ou dos vizinhos de seu bairro?". As respostas foram codificadas da seguinte maneira: "não" como "baixo" (=1) e "sim" como "elevado" estoque de capital social $(=0)$.

${ }^{1}$ Pergunta: "Agora eu vou falar de assunto polêmico. O que o(a) sr(a) acha de homens que fazem sexo com homens?". As respostas foram codificadas da seguinte maneira: "essas pessoas não têm vergonha" e "essas pessoas são doentes" como "intolerância" $(=1)$ e "as pessoas são livres para fazer o que querem" como "tolerância" em relação à homossexualidade (=0).

${ }^{2}$ Pergunta: "Na sua opinião: 1. A democracia é sempre melhor que qualquer outra forma de governo ou 2. Em algumas situações é melhor uma ditadura do que uma democracia?". As respostas foram codificadas da seguinte maneira: "em algumas situações é melhor uma ditadura do que uma democracia" e "tanto faz" como "baixo" $(=1)$ e "a democracia é sempre melhor que qualquer outra forma de governo" como "elevado" apoio à democracia $(=0)$.

Fonte: LAPOP-Brasil, 2007.

Assim como indivíduos com poucos anos de escolaridade formal, pessoas mais idosas também têm maior propensão a possuir valores não-igualitários no que se refere a gênero e política. Nesse sentido, a probabilidade de brasileiros com 61 anos ou mais rejeitarem a presença de uma mulher na cadeira presidencial é aproximadamente 9,5\% maior do que a de um(a) jovem de $16 \cdot 17$ anos.

A intersecção entre gênero e raça, controlada por diferentes níveis de renda (um indicador de classe social), não produz resultados estatisticamente significantes (Modelo 1). Pessoas que se auto-definem como brancas, no entanto, têm uma maior probabilidade de portar valores igualitários em relação a gênero (Modelo 3). Isso pode ser uma conseqüência de outras variáveis, como educação dado que raça, no Brasil como em muitos outros países, não é somente uma 
BOHN, S. R. Mulher para presidente do Brasil? Gênero e política...

categoria étnico-biológica, mas sobretudo social. Na amostra LAPOP-Brasil 2007, por exemplo, entre os indivíduos que concluíram o ensino superior (graduação ou mais), 71,4\% são brancos - e não há pessoas que se auto-identificam como negras nessa faixa educacional. Portanto, há que se ler com muito cuidado resultados deste tipo.

No que se refere ao plano das opiniões, aqueles que rejeitam o princípio da participação eqüitativa da mulher na arena política formal tendem a esposar valores semelhantes em outras esferas, como o mercado de trabalho. Assim sendo, esses indivíduos têm maior probabilidade de concordar com a idéia de que "quando o desemprego é elevado, os homens têm mais direito ao trabalho do que as mulheres". São, além disso, bastante coerentes em suas opiniões, já que também têm maior chance de concordar que "as mulheres ainda não têm experiência suficiente para governar" e que "os homens governam melhor dos que as mulheres". Ou seja, crêem que no universo político formal - e também no mercado de trabalho - deve predominar uma lógica essencialmente masculina e, que, aparentemente, essa estrutura patriarcal deva ser mantida (MELO, CONSIDERA e DI SABBATO, 2007; GROSSI e MIGUEL, 2001).

Um ponto interessante emerge quando observamos os dados a respeito da variável capital social. Eles inequivocamente revelam que quanto maior o grau de engajamento e participação de um indivíduo em associações da sociedade civil, menor a probalidade de ele ou ela rejeitar a igualdade de gênero na esfera política formal. Isso significa que, conforme sugere Putnam (1993) para o caso da Itália, maior grau de associativismo cívico conduz ao desenvolvimento de valores democráticos, igualitários, de tolerância e aceitação da diversidade social.

Finalmente, os dados demonstram que aqueles que rejeitam a igualdade de gênero no plano político formal são igualmente intolerantes em relação a outros grupos sociais minoritários e não vêem a democracia como um bem inegociável. Pelo contrário, os indivíduos que esposam valores não-igualitários em relação às mulheres, são extremamente intolerantes em relação, por exemplo, à homossexualidade. Consideram-na como uma imoralidade ou uma doença - e, portanto, como algo socialmente indesejável e/ou inaceitável.

Em termos do grau de apoio ao regime democrático, as pessoas adeptas de uma visão patriarcal em relação aos papéis dos dois gêneros, em sua maior parte, acreditam que em algumas situações uma ditadura é melhor que uma democracia ou que tanto faz que um regime seja democrático ou autoritário. Inversamente, democratas inequívocos (ou seja, aqueles que consideram a democracia sempre melhor do que qualquer outra forma de governo) têm maior probabilidade de aceitar o princípio da igualdade de gênero.

Esses dois dados, em conjunto, revelam que a minoria dos brasileiros resistente à idéia de uma mulher ocupando a Presidência da República não possui 
valores tradicionais somente no que se refere à questão de gênero. Pelo contrário, são pessoas cuja visão tradicional de mundo se manifesta de maneira similar em diversas outras esferas sociais. O perfil valorativo, atitudinal e comportamental dessa minoria sugere que o impacto do processo de modernização sobre o sistema de valores foi, no caso brasileiro, heterogêneo. Em outras palavras, resultou na permanência de bolsões de valores tradicionais disseminados pela sociedade brasileira.

\section{Conclusões}

Este artigo buscou verificar se, conforme defendido pelas diferentes correntes da teoria da modernização, as macro-transformações socioeconômicas que levam à passagem de sociedades agrárias para sociedades industriais (e, mais tarde, pós-industriais) de fato se correlacionam com a mudança no sistema de valores, na direção de uma weltanchauung tradicional para uma visão de mundo "moderna" (ou pós-materialista), ou seja, secular-racional e de auto-expressão. 0 valor fundamental no qual nos focamos consistiu na aceitação do princípio da igualdade de gênero no campo da política formal. De acordo com a literatura aqui discutida, em sociedades mais desenvolvidas economicamente (isto é, industrializadas ou na sua fase pós-industrial), a idéia da participação eqüitativa da mulher - não só na política, mas em todas as áreas de convívio social - é amplamente aceita e difundida em todos os segmentos sociais.

Mostramos que este também é o caso do Brasil. A maioria da população, pelo menos em tese, revela-se favorável à aceitação da igualdade de gênero na política 5 . Esta maioria, ao ratificar, por exemplo, a idéia de que o gênero dos candidatos não é o elemento decisivo no processo de escolha eleitoral, parece rejeitar visões patriarcais do universo político, que são típicas de sociedades nas quais valores tradicionais predominam.

Os principais preditores de valores igualitários no que se refere ao gênero são idade, nível educacional e sobretudo o estoque de capital social dos indivíduos. A intolerância em relação à igualdade de gênero tende a diminuir ou inexistir entre as pessoas no topo da escala educacional. Há, além disso, como vimos, um corte geracional significativo entre a população brasileira. Pessoas mais jovens tendem em maior grau a esposar valores igualitários do que indivíduos nascidos antes de 1946 - que foram socializados em um país preponderantemente agrário, rural e

\footnotetext{
5 Ou seja, como sociedade modernizada, o sistema valorativo da maioria da população brasileira claramente reflete as expectativas da teoria da modernização. Não podemos testar aqui o grau ou tamanho da mudança no sistema de valores. Para isso, necessitaríamos de surveys realizados antes dos anos quarenta.
} 
BOHN, S. R. Mulher para presidente do Brasil? Gênero e política...

com um índice elevado de analfabetismo. Finalmente, maior associativismo cívico também se correlaciona fortemente com maior propensão ao desenvolvimento de valores igualitários.

Apesar dessa difusão ampla de valores que evidenciam a aceitação da igualdade de gênero no Brasil, há uma minoria de brasileiros (12,0\%) bastante resistente a esse princípio. Doze por cento, em tese, equivalem a cerca de vinte milhões de brasileiros - um número não desprezível em termos absolutos (IBGE, 2000). Esses indivíduos não só atribuem papéis tradicionais ao segmento feminino da população - o que afasta as mulheres do universo político -, como também se revelam intrinsecamente intolerantes e autoritários. De forma alguma aceitam a homossexualidade, por exemplo, - evidenciando seu baixo respeito por outras minorias sociais e corroborando, embora de maneira inversa, a visão de alguns autores (como Inglehart e Norris, 2005) de que atitudes de tolerância criam uma espécie de cesta de valores igualitários que se manifestam em todas as esferas de interação social.

O dado mais preocupante a respeito dessa minoria é o fato de ela também ser preponderantemente autoritária. O regime democrático não é por eles percebido como a melhor forma de governo. Pelo contrário, não atribuem à democracia o caráter de um valor inegociável. Se a democracia é um "universal evolucionário" (PARSONS, 1999) ou mesmo um "valor universal" (SEN, 1999b), temos que concluir que, no Brasil, atualmente, uma cultura política híbrida predomina. Valores modernos e pós-modernos difusos entre a maior parte da sociedade são acompanhados por valores tipicamente tradicionais concentrados em uma minoria da população. Resta-nos saber, se focássemos a análise em outros valores - como, por exemplo, a igualdade de opção religiosa ou sexual -, se essa minoria realmente se restringiria a pouco mais de um décimo da população ou se seria bem mais ampla. 


\section{Referências bibliográficas}

ADAMS, J. e ORLOFF, A. S. "Defending Modernity? High Politics, Feminist Anti-Modernism, and the Place of Gender", Politics \& Gender, vol.1, n²1, 2005.

ALMEIDA, A. "O Brasil no Final do Século XX: Um caso de Sucesso". Dados, vol. 41, n4, 1998.

ARAÚJO, C. e SCALON, C. "Gênero e a distância entre a intenção e o gesto". Revista Brasileira de Ciências Sociais, vol. 21, n62, 2006.

ARISTÓTELES. A Política. São Paulo: Martins Fontes, 1998.

BAKER, K. Condorcet: From Natural Philosophy to Social Mathematics. University of Chicago Press, 1975.

BARBER, B. The logic and limits of trust. New Brunswick, NJ: Rutgers University Press, 1983.

BELL, D. The Coming of Post-Industrial Society: A Venture in Social Forecasting. New York: Basic Books, 1973.

BELLO, W. Dark Victory: The United States, Structural Adjustment and Global Poverty. London: Pluto, 1994.

BENNETT, L. e BENNETT, S. Changing Views about Gender Equality in Politics: Gradual Change and Lingering Doubts. In: WHITAKER, L. (ed.). Women in Politics: Outsiders or Insiders? Upper Saddle River: Prentice Hall, 1999.

BOBBIO, N. O Futuro da Democracia. Rio de Janeiro: Paz e Terra, 1986.

BOSERUP, E. Women's Role in Economic Development. London: Allen \& Unwin, 1974.

BOTTOMORE, T. e NISBET, R. A History of Sociological Analysis. Basic Books, 1978.

BOURDIEU, P. The forms of capital. In: RICHARDSON, J.G. (ed.). Handbook for theory and research for the sociology of education. New York: Greenwood Press, 1986. 
BREWER, R. "Theorizing Race, Class and Gender: The New Scholarship of Black Feminist Intellectuals and Black Women's Labor". Race, Gender and Class, vol. 6, n², 1999.

BRZEZINSKI, Z. "The New Challenges to Human Rights". Journal of Democracy, vol. 8, n², 1997.

BURNS, N.; SCHOLZMAN, K.; VERBA, S. The Private Roots of Public Action. Cambridge, MA: Harvard University Press, 2001.

BURREL, B. A Woman's Place is in the House: Campaigning for Congress in the Feminist Era. Ann Arbor, MI: University of Michigan Press, 1994.

CARREIRA, D. (ed.). Igualdade de Gênero no Mundo do Trabalho: Projetos Brasileiros que Fazem a Diferença. São Paulo/Brasília: Cortez/Fundo de Gênero Brasil-Canadá, 2004.

CARDOSO, F. H. e FALETTO, E. "Comprehensive analysis of development". Dependency and development in Latin America. California: University of California Press, 1979.

COLEMAN, J. A Rational Choice Perspective on Economic Sociology. In: SMELSER, N. (ed.). The Handbook of Economic Sociology. Princeton: Princeton University Press, 1994.

COLEMAN, J. "Social capital in the creation of human capital". American Journal of Sociology, Supplement: Organizations and Institutions: Sociological and Economic Approaches to the Analysis of Social Structure, vol. 94, 1988.

COLLINS, P. H. Black Feminist Thought. Boston: Unwin Hyman, 1990.

vol.13, n³, 1998.

"It's all in the Family: Intersections of Gender, Race and Nation". Hypatia,

CRENSHAW, K. Demarginalizing the Intersection of Race and Sex: A Black Feminist Critique of Antidiscrimination Doctrine, Feminist Theory and Antiracist Politics. In WEISBERG, K. (ed.). Feminist Legal Theory: Foundations. Philadelphia: Temple University Press, 1993.

"Mapping the Margins: Intersectionality, Identity Politics and Violence Against Women of Color". Stanford Law Review, vol.43, n6, 1991. 
DAVIS, N. e ROBINSON, R. "Men and Women's Consciousness of Gender Inequality: Austria, West Germany, Great Britain, and the United States". American Sociological Review, vol.56, $\mathrm{n}^{\circ} 1,1991$.

DEUTSCH, K. "Social Mobilization and Political Development". American Political Science Review, vol.55, n³, 1961.

DURKHEIM, E. The Division of Labor in Society. New York: Free Press, 1997.

ENLOE, C. Bananas, Bases and Beaches: Making Feminist Sense of International Relations. London: Pandora Books, 1989. "Silicon Tricks and the Two Dollar Woman". New Internationalist, July, 1992.

Maneuvers: The International Politics of Militarizing Women's Lives. London: University of California Press, 2000.

Gender and Politics. In: KRIEGER, J. (ed.). The Oxford Companion to Politics of the World. New York: Oxford University Press, 2001.

FERBER, A. "Deconstructing Whiteness: The Intersections of Race and Gender in White Supremacist Thought". Ethnic and Racial Studies, vol.21, n¹, 1998.

FINAMORE, C. M. e CARVALHO, J. E. C. "Mulheres Candidatas: Relações entre Gênero, Mídia e Discurso". Estudos Feministas, vol.14, n², 2006.

FLAX, J. "Postmodernism and Gender Relations in Feminist Theory", Signs, 1987.

FRIEDAN, B. The Feminine Mystique. New York: Dell, 1963.

FUKUYAMA, F. Trust. New York: New York Free Press, 1997.

GERMANI, G. Industrialization and modernization. In: Sociology of modernization. New Brunswick, NJ: Transaction Books, 1981. 
GIDENGIL, E. e O'NEILL, B. Removing Rose Colored Glasses. Examining Theories of Social Capital through a Gendered Lens. In: GIDENGIL, E. e O'NEILL, B. (eds.). Gender and Social Capital. New York: Routledge, 2006.

GROSSI, M., e MIGUEL, S. M. "Transformando a diferença: as mulheres na política”. Estudos Feministas, vol.9, $\mathrm{n}^{\circ} 1,2001$.

GULATI, G. "Members of Congress and presentation of self on the World Wide Web". Harvard International Journal of Press Politics, vol.9, $\mathrm{n}^{\circ} 1,2004$.

HTUN, M. Sex and the State: Abortion, Divorce, and the Family Under Latin American Dictatorships and Democracies. New York: Cambridge University Press, 2003.

IBGE. Evolução e Perspectivas da Mortalidade Infantil no Brasil. Rio de Janeiro: IBGE, 1999.

Censo Demográfico 2000. Rio de Janeiro: IBGE, 2000. Disponível em:

<http://www.ibge.gov.br/home/estatistica/populacao/censo2000/tabelabrasil111.shtm>. Acesso em: 21 maio 2008.

. Projeção da População do Brasil. Parte 1 - Níveis e padrões da mortalidade no

Brasil à luz dos resultados do Censo 2000. Rio de Janeiro: IBGE, 2003.

INGLEHART, R. The Silent Revolution: Changing Values and Political Styles among Western Publics. Princeton: Princeton University Press, 1977.

Press, 1990 . Culture Shift in Advanced Industrial Society. Princeton: Princeton University Modernization and Postmodernization: Cultural, Economic and Political Change in 43 Societies. Princeton: Princeton Unversity Press, 1997.

INGLEHART, R. e BAKER, W. "Modernization, Cultural Change and the Persistence of Traditional Values", American Sociological Review, vol.65, n¹, 2000.

INGLEHART, R. e NORRIS, P. Rising Tide: Gender Equality and Cultural Change Around the World. New York: Cambridge University Press, 2003. 
"Modernization and Gender Equality: A Response to Adams and Orloff".

Politics and Gender, vol.1, n³, 2005.

INGLEHART, R. e WETZEL, C. Modernization, Cultural Change and Democracy. New York: Cambridge University Press, 2005.

JAKOBSEN, K. et al (eds). Mapa do Trabalho Informal: Perfil Socioeconômico dos Trabalhadores Informais na Cidade de São Paulo. São Paulo: CUT/Fundação Perseu Abramo, 2000.

JAGUARIBE, H. Considerações Finais. In: JAGUARIBE, H. et al. Brasil, Sociedade Democrática. Rio de Janeiro, José Olympio, 1985.

JAQUETTE, J. "Women and Modernization Theory: A Decade of Feminist Criticism". World Politics, vol.34, $\mathrm{n}^{\circ} 2,1982$.

JOHNSON, N. In Pursuit of the Right to be Free from Violence: the Women's Movement and State Accountability in Uruguay. In: CRASKE, N. e MOLYNEUX, M. (eds.). Gender and the Politics of Rights and Democracy in Latin America. New York: Palgrave, 2002.

JOHNSTON, D. Constructing the Periphery in Modern Global Politics. In: MURPHY, C. e TOOZE, R. (eds.). The International Political Economy. Boulder, CO: Lynne Rienner, 1991.

LERNER, D. The Passing of Traditional Society: Modernizing the Middle East. New York: Free Press, 1958.

LIPSET, S. M. "Some social requisites of democracy: Economic development and political legitimacy". American Political Science Review, vol.53, n¹, 1959.

Political Man: The Social Bases of Politics. Garden City: Doubleday, 1960.

LOPES, C. M. S. "Direito do trabalho da mulher: da proteção à promoção". Cadernos Pagu, $n^{\circ} 26,2006$.

LOWNDES, V. “Women and Social Capital: A Comment on Hall's 'Social Capital in Britain'”. British Journal of Political Science, vol.30, n³, 2000. 
MARSHALL, T. H. Citizenship, social class and status. In: Citizenship, social class and other essays. Cambridge: Cambridge University Press, 1950.

MARX, K. Foundations of the Critique of Political Economy. New York: Vintage Books, 1973.

MELO, H. P.; CONSIDERA, C. M. e DI SABBATO, A. "Os Afazeres Domésticos Contam". Economia \& Sociedade, vol.16, n³, 2007.

MOLYNEUX, M. "Gender and the Silences of Social Capital: Lessons from Latin America". Development and Change, vol.33, $\mathrm{n}^{\circ} 2,2002$.

MONROE, K.; OZYURT, S.; WRIGLEY, T. e ALEXANDER, A. "Gender Equality in Academia: Bad News from the Trenches, and Some Possible Solutions". Perspectives on Politics, vol.6, $\mathrm{n}^{\circ} 2$, 2008.

ONDERCIN, H. e WELCH, S. Women candidates for Congress. In: SUE, T. e WILCOX, C. (eds.). Women and elective office: past, present, and future. New York: Oxford University Press, 2005.

PALDAM, M. "Social Capital: One or Many? Definition and Measurement". Journal of Economic Surveys, vol.14, n5, 2000.

PARSONS, T. Evolutionary universals in society. In: TURNER, B. S. (ed). The Talcott Parsons Reader. Malden, MA e Oxford: Blackwell, 1999.

PETERSON, V. S. e RUNYAN, A. S. Global Gender Issues. Boulder, CO: Westview Press, 1999.

PUTNAM, R. Bowling Alone: The Collapse and Revival of American Community. New York: Simon \& Schuster, 2000.

. Making Democracy Work: Civic Traditions in Modern Italy. Princeton: Princeton University Press, 1993.

$\mathrm{n}^{0} 24,1996$.

. "The Strange Disappearance of Civic America". The American Prospect, vol.7,

$n^{\circ} 1,1995$.

"Bowling Alone: America's Declining Social Capital". Journal of Democracy, vol.6, 
RANDALL, V. e THEOBALD, R. Political Change and Underdevelopment: A Critical Introduction to Third World Politics. Durham: Duke University Press, 1985.

ROSTOW, W. The Stages of Economic Growth. Cambridge: Cambridge University Press, 1960.

SAID, E. Orientalism. New York: Vintage, 1979.

SANBONMATSU, K. "Gender, stereotypes and voto choice". American Journal of Political Science, vol.46, p.20-34, 2002.

SANTOS, W. G. A Pós-'Revolução' Brasileira. In: JAGUARIBE, H. et al. Brasil, Sociedade Democrática. Rio de Janeiro: José Olympio, 1985.

"O Estado Social da Nação". Dados, vol. 29, n 3, 1986.

SCHUMPETER, J. A. Capitalism, Socialism and Democracy. London: Allen \& Unwin, 1976.

SCOTT, C. V. Gender and Development: Rethinking Modernization and Dependency Theory. Boulder, CO: Lynne Rienner, 1995.

SEN, A. Development as Freedom. New York: Anchor Books, 1999a.

"Democracy as a Universal Value”. Journal of Democracy, vol.10, n³, 1999b.

STEEL, G. e KABASHIMA, I. "Cross-Regional Support for Gender Equality". International Political Science Review, vol. 29, $n^{\circ} 2,2008$.

TOCQUEVILLE, A. Democracy in America. New Cork: Mentor, 1994.

VARGAS, V. The Struggle by Latin American Feminisms for Rights and Autonomy. In: CRASKE, N. e MOLYNEUX, M. (eds.). Gender and the Politics of Rights and Democracy in Latin America. New York: Palgrave, 2002.

WAYLEN, G. Engendering Transitions: Women's Mobilization, Institutions, and Gender Outcomes. Oxford: Oxford University Press, 2003. 
WELDON, S. L. Intersectionality. In GOERTZ, G. e MAZUR, A. (eds.). Politics, Gender and Concepts: Theory and Methodology. Cambridge: Cambridge University Press, 2008.

WEBER, M. The Protestant Ethics and the Spirit of Capitalism. New York: Scribner's Sons, 1958.

WILLMOTT, C. Constructing Citizenship in the Plobaciónes of Santiago, Chile: the Role of Reproductive and Sexual Rights. In: CRASKE, N. e MOLYNEUX, M. (eds.). Gender and the Politics of Rights and Democracy in Latin America. New York: Palgrave, 2002.

WORLD BANK. Addressing Gender Equality: World Bank Action Since Beijing. Washington, DC: World Bank, 2000. 